\title{
El «ángulo muerto» del Derecho Internacional: las empresas transnacionales y sus cadenas de suministro
}

\author{
The «Dead Angle» of International Law: \\ Transnational Corporations and theirs Supply Chains
}

\author{
Lorena SALEs Pallarés \\ Universidad de Castilla-La Mancha \\ lorena.sales@uclm.es
}

\author{
Maria Chiara MARULlo \\ Universitat Jaume I \\ marullo@uji.es
}

\begin{abstract}
Resumen: La creación de normas vinculantes y la búsqueda de recursos efectivos para las víctimas de graves violaciones de derechos humanos cometidas por empresas transnacionales, han sido y son, los objetivos de la lucha más difícil a la que se enfrentan los defensores de los derechos humanos en todo el mundo. A nivel internacional, muchos han sido los intentos de creación de normas vinculantes sobre la protección de los derechos humanos en el ámbito de las empresas. El «ángulo muerto» del derecho internacional hace referencia al hecho de que en la actualidad no existen normas de hard law capaces de responsabilizar a las corporaciones internacionales por los graves ilícitos internacionales perpetrados extraterritorialmente en sus cadenas de suministro. La finalidad de este trabajo es tomar conciencia de este problema y al mismo tiempo evaluar mecanismos, estrategias y acciones desde la perspectiva civil, para garantizar el derecho de acceso a la justicia, y con ello, colmar en parte este «ángulo muerto» del derecho internacional.
\end{abstract}

Palabras clave: derecho internacional; derechos humanos; cadenas de suministros; empresas transnacionales.

\begin{abstract}
The implementation of binding norms and the search for effective remedies for victims of serious human rights violations committed by transnational corporations have been and continue to be the objectives of the most difficult struggle that human rights defenders are facing all over the world. At the international level, many attempts have been made to create binding rules on human rights and business. The «dead angle» of international law refers to the fact that actually there are no hard law norms capable of holding corporations responsible for the serious internationally wrongful perpetrated extraterritorially by their supply chains. The purpose of this work is to become aware of this problem, while evaluating other mechanisms, strategies and actions from a civil perspective, to guarantee the right of access to justice in an attempt to fill partially this «dead angle» of international law.
\end{abstract}

Keywords: international law; human rights; supply chains; transnational corporations 


\section{Estado DE LA CUESTIÓN}

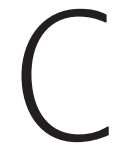

onstituye hoy en día la interacción entre los derechos humanos y las empresas transnacionales uno de los mayores objetos de estudio y atención por parte de la comunidad internacional ${ }^{1}$. La creación de normas vinculantes y la búsqueda de recursos efectivos para las víctimas, han sido y son, los objetivos de la lucha más difícil a la que se enfrentan los defensores de los derechos humanos en todo el mundo ${ }^{2}$.

El poder que como actores económicos y sociales han adquirido las empresas, es innegable, pudiéndose ver y sentir a todos los niveles. Así, se ha demostrado y puesto en evidencia el creciente poder y control que algunas de las más importantes empresas están teniendo a nivel mundial ${ }^{3}$. Esta acumulación de poder resulta más peligrosa en sectores como la energía, el agua ${ }^{4}$ la

1 Para más información véase Marullo, $M^{a}$ Ch. y Zamora Cabot, F.J. (eds.), Empresas y Derechos Humanos, Scientifica, Nápoles, 2018.

2 De esta forma se ha expresado ZAMORA CABOT enfatizando en diferentes ocasiones el esfuerzo realizado por los académicos y activistas a nivel mundial en la defensa de los Derechos Humanos y en la lucha contra la impunidad de las multinacionales para garantizar remedios efectivos a las víctimas de ilícitos internacionales. V. gr. ZAMORA CABOT, F.J., «Acaparamiento de tierra (land grabbing) y empresas multinacionales: el caso Mubende-Neumann», Papeles el tiempo de los derechos, 5 (2013), <http://e-archivo.uc3m.es/bitstream/handle/10016/19292/acaparamiento_zamora_PTD_2013.pdf?sequence $=1>(8$ de febrero 2018). Véase también NoLAN, J., «Business and Human Rights: The Challenge of Putting Principles into Practice and Regulating Global Supply Chains», Alternative Law fournal, 42 (1), January 1 (2017) (UNSW Law Research Paper n. ${ }^{\circ} 33$. Available at SSRN: <https://papers.ssrn.com/sol3/papers.cfm?abstract_id=2981494>).

3 Clarke, T. y Boersma, M., «The Governance of Global Value Chains: Unresolved Human Rights, Environmental and Ethical Dilemmas in the Apple Supply Chain», Fournal of Business Ethics, vol. 143, issue 1 (2017), pp. 111 y ss.; Chilton, A.S. y SARFaTY, G.A., «The limitations of supply chain disclosure regimes», Stanford fournal of International Law, vol. 53, issue 1 (2017), pp.1 y ss.; Muchlinski, P. T., Multinational Enterprises and the Law, $2^{2}$ ed., Oxford University Press, 2007, p. 119; MarTín-OrTega, O., Empresas multinacionales y Derechos Humanos en Derecho Internacional, Bosch, 2008, p. 92; Vitali, S.; GlatTFElder, J.B. y BatTiston, S., «The Network of Global Corporate Control», septiembre 2011, <http://arxiv.org/pdf/1107.5728. pdf> (4 de febrero de 2018).

4 Véase entre otros, SÁNChEZ Bravo, Á. A., «Injusticia ambiental y derecho humano al agua», en Fusticia y medio ambiente, Sevilla, 2013, pp.151 y ss.; MENÉNDEZ REXACH, Á., «El agua como bien jurídico global: el derecho humano al agua», Anuario de la Facultad de Derecho de la Universidad Autónoma de Madrid, n. ${ }^{\circ} 16$ (2012), pp.187 y ss.; y ZAMORA CABOT, F.J. y CAMARERO SuAREZ, $M^{a}$.V., «En torno al derecho humano al agua y el saneamiento en la Carta Encíclica Laudato Si' del Santo Padre Francisco», Revista de Derecho, Agua y Sostenibilidad (REDAS), n. ${ }^{\circ}$ 0, \$ V.2 (2016), pp.1 y ss., <http://redas.webs.uvigo.es/images/biblio/bibliografia_derecho_humano_agua.pdf> (4 de febrero de 2018). 
extracción de gas y petróleo, ya que en estos campos resulta fácil comprobar cómo pueden afectar al bienestar de la humanidad ${ }^{5}$.

En este sentido parecería por tanto justo contar con mecanismos para poder exigirles responsabilidades cuando el ejercicio de su actividad empresarial produjera, o consintiera, violaciones de derechos humanos. Paradójicamente, y a pesar de que una gran mayoría de la población y de la doctrina científica estaría de acuerdo con esto, sigue siendo un tema muy controvertido debido a diferentes factores. Posiblemente uno de los que más pesan sea el llamado revolving doors ${ }^{6}$, que deja traslucir cómo los poderes, legislativos y ejecutivos, internacionales y nacionales, ceden ante los intereses del mercado. La simbiosis que así se produce, provoca que no se cuente casi con normativa (ni bard law ni soft law) para estos casos y que en último término se deje sin acceso a la justicia a una gran mayoría de estos afectados. El resultado final: un clamoroso silencio de justicia material.

Cuando las empresas transnacionales (y sus cadenas de suministros) por acción o por omisión provocan violaciones de derechos humanos deberían responder ante el poder judicial. Esto implicaría la existencia de acciones para las víctimas o los afectados por estas violaciones. Sin embargo, y ahí es donde hablamos del «ángulo muerto» del derecho internacional, en la actualidad no existen normas de hard law capaces de responsabilizar a las corporaciones internacionales (ni a sus cadenas de suministros) por los graves ilícitos internacionales perpetrados extraterritorialmente.

La finalidad de este trabajo es tomar conciencia de este problema y revisar los mecanismos, estrategias y acciones con los que contamos y que puedan garantizar el derecho de acceso a la justicia, y con ello, colmar en parte este «ángulo muerto» del derecho internacional. Así se analizarán las normas de

5 Véanse entre otros, FrISCH, W., «Derecho penal y protección del clima: Posibilidades y límites de una contribución del Derecho penal a la protección del clima conforme a convenios internacionales», Indret: Revista para el Análisis del Derecho, n. ${ }^{\circ} 4$ (2015), pp.1 y ss.; ZAMORA Cabot, F.J.; García Cívico, J. y Sales Pallarés, L. (eds.), La responsabilidad de las multinacionales por violaciones de derechos humanos, Universidad de Alcalá, Servicio de Publicaciones, Alcalá, 2013.

6 Nos estamos refiriendo al fenómeno que en el mundo anglosajón se conoce como «puertas giratorias», por el cual se produce una circulación sin obstáculos de altos cargos entre los sectores público y privado. Estos movimientos se producen en un sentido y en otro, es decir, desde las instituciones públicas a las empresas transnacionales y viceversa, constituyendo una muestra de lo difusa que es la línea que separa ambos poderes, el político y el económico, y que se basa en la obtención recíproca de privilegios o beneficios. 
soft $l a w^{7}$, como respuesta a esta falta de normativa, así como las iniciativas que se han desarrollado para atajar esta situación. En concreto, se prestará atención a la solución californiana de supervisión de las cadenas de suministro con el fin de poder extraer conclusiones de su actuación para adaptarlas a la regulación comunitaria.

\section{EL «ÁNGULO MUERTO» DEL SISTEMA INTERNACIONAL}

$\mathrm{Al}$ poco de percibirse el problema que representaba el cruce de empresas y derechos humanos, surgieron múltiples intentos a nivel internacional de creación de normas vinculantes para la protección de los derechos humanos en el ámbito de la empresa. Entre otras, toca mencionar las Normas de la ONU sobre la responsabilidad de las empresas transnacionales y otras empresas en relación a los derechos bumanos ${ }^{8}$, o la Declaración de Ginebra sobre las prácticas responsables de las empresas 20079. Lamentablemente el «ángulo muerto» del derecho internacional ${ }^{10}$ hace referencia al hecho de que a pesar de estas iniciativas en la actualidad no existen normas de hard law capaces de responsabilizar y sancionar a las corporaciones por los graves ilícitos perpetrados extraterritorialmente en sus cadenas de suministro ${ }^{11}$.

7 Entendiendo como tales aquellos instrumentos que sin ser vinculante ni constituir normas jurídicas en sentido estricto, vinculan e influyen sobre la praxis de los Estados en una determinada materia. Sobre este aspecto TANZI afirma que: «Si tratta di quegli strumenti non vincolanti giuridicamente che, tuttavia, tendono a fare parte delle dinamiche di formazione di obblighi giuridici internazionali secondo processi diplomatici e logico-giuridici in base al principio generale della buona fede». Vid. TANZI, A., Introduzione al diritto internazionale pubblico, CEDAM, Padova, 2013, p. 63.

8 E/CN.4/Sub.2/2003/12/Rev.2 de 26 de agosto de 2003.

9 Más información en <http://www.un.org/press/en/2007/eco119.doc.htm>, 2007 (10 de febrero de 2018).

10 Sobre este tema, ReQuejo IsIDRO, M., «La responsabilidad de las empresas por violación de derechos humanos: deficiencias del marco legal», Scientia Iuris (Université Paul Verlain, Metz) vol. 1 (May 2011), pp. 10 y ss., <http://www.revuegeneraledudroit.eu/wp-content/uploads/ scientia01theme_requejo.pdf $>, 2011$ (10 de febrero de 2018).

11 Lund-Thomsen, P. y Lindgreen, A., «Corporate Social Responsibility in Global Value Chains: Where Are We Now and Where Are We Going?», Fournal of Business Ethics, vol. 123, issue 1 (August 2014), pp.11 y ss.; Nolan, J., «Refining the Rules of the Game: The Corporate Responsability to Respect Human Rights», Utrech fournal of International and European Law, 30 (78), pp.7 y ss. DOI: <http://dx.doi.org/10.5334/ujiel.ca>; GOMES, W., «Reason and Responsibility: the Rana Plaza Collapse», <https://www.opendemocracy.net/opensecurity/william-gomes/ reason-and-responsibility-rana-plaza-collapses, 2013 (15 abril 2016); TER HAAR, B.P. y 
No obstante, los diferentes intentos y normas de soft law en la materia demuestran que se está cambiando la visión de la protección de los derechos humanos, no simplemente como reivindicación de los individuos a los poderes públicos sino también frente al sector privado ${ }^{12}$. Por lo tanto, tomando conciencia de la existencia de este problema, esto es, la falta de normativa de hard law, en este trabajo enfatizamos la posibilidad que las normas de soft law ofrecen de crear otros mecanismos, nuevas estrategias y acciones a nivel estatal o regional para garantizar el derecho de acceso a la justicia y con ello, colmar este «ángulo muerto» del derecho internacional. Conscientes de la multitud de perspectivas desde la que se puede abordar el tema de la responsabilidad de las transnacionales, hemos decidido centrar nuestra atención al enfoque de la responsabilidad civil sobre las cadenas de suministro de las empresas transnacionales, desde la perspectiva del Derecho Internacional Privado.

\subsection{El acceso a la justicia en el marco Proteger, Respetar y Reparar}

Hace ya una década, el profesor RUGGIE ${ }^{13}$ declaró que las brechas de gobernanza creadas por la globalización estaban proporcionando el ambiente permisivo para actos ilícitos por parte de empresas de todo tipo sin una sanción o reparación adecuada para las víctimas. En 2006, en su Informe so-

Keune, M., «One Step Forward or More Window-Dressing? A Legal Analysis of Recent CSR Initiatives in the Garment Industry in Bangladesh», International fournal of Comparative Labour Law and Industrial Relations, vol. 30, issue 1 (2014), pp. 5 y ss.; EvANS, B.A., «Accord on Fire and Building Safety in Bangladesh: An International Response to Bangladesh Labor Conditions», North Carolina Fournal of International Law and Commercial Regulation, 40 (2014-2015), pp.597 y ss.; Boudreau, L.; MaKioka, R. y TANaKa, M., «The Impact of the Rana Plaza Collapse on Global Retailers», <http://web.stanford.edu/ mrtanaka/Mari\%20Tanaka\%20-\%20PhD\%20 Candidate\%20-\%20Stanford_files/rana_retailers151213.pdf>(15 abril 2016).

12 Sobre este tema, Aymerich OJEA, I., «Orígenes ideológicos de la distribución de responsabilidades públicas y privadas en la garantía de los derechos humanos», en La responsabilidad de las multinacionales..., op.cit., pp. 21 y ss.

13 El profesor John RUGGIE fue nombrado Representante Especial de la ONU para la cuestión de los derechos humanos y las empresas transnacionales y otras empresas de 2005 a 2011. La importancia de sus estudios tiene la culminación en los denominados «Principios Ruggie», presentados en su Informe final ante Naciones Unidas, bajo el título Principios Rectores sobre las empresas $y$ los derechos humanos: puesta en práctica del marco de las Naciones Unidas para «proteger, respetar y remediar» (A/HRC/17/31, de 21 de marzo de 2011, cuya versión en español se puede consultar en <http://www.global-business-initiative.org/wp-content/uploads/2012/07/GPs-Spanish. pdf>, 2012 (31 de enero de 2018). 
bre esta cuestión ${ }^{14}$, ponía de manifiesto las múltiples razones para hablar de una responsabilidad compartida entre Estados y empresas en la promoción y protección de los derechos fundamentales. En el mismo informe, el autor evidenciaba como, debido a las recientes catástrofes medioambientales y las graves violaciones de derechos humanos y laborales cometidas por empresas trasnacionales, se había intensificado en los últimos años la labor de los legisladores nacionales y supranacionales empeñados en minimizar los riesgos de las actividades empresariales y mitigar los impactos negativos.

Bajo esta óptica desarrolló en 2008 un mecanismo alternativo, voluntario, no vinculante, para la protección y garantía de los derechos humanos, bajo el lema Proteger, Respetar y Reparar ${ }^{15}$. Sin dudar de su importancia, es cierto que para no quedar en letra muerta se hace necesaria su implementación en normativas nacionales ${ }^{16}$, pero, aunque sea norma de soft law, este marco ha desempeñado un importante papel mirando de cerca las consecuencias directas generadas en el tema de creación de normas, tanto a nivel nacional como internacional ${ }^{17}$. La creación de normas de hard law en esta materia es un proceso muy complejo, lleno de obstáculos y lento, por lo tanto, hay que valorar cómo las normas de soft law (presentes y futuras) pueden aportar algo constructivo para lograr resultados.

En todo caso, los Principios Ruggie abrieron las puertas a la lucha contra la impunidad de las corporaciones auspiciando un atento debate sobre el acceso

14 Promoción y Protección de los Derechos Humanos, Informe provisional del Representante Especial del Secretario General sobre la cuestión de los derechos humanos y las empresas transnacionales y otras empresas comerciales, Distr. GENERAL E/CN.4/2006/97 del 22 de febrero de 2006, que se puede consultar en <https://business-humanrights.org/sites/default/files/media/bhr/files/Ruggie-HRC2006-Es.pdf>, 2006 (23 de enero de 2018).

15 Conocidos como «Principios Ruggie», sobre los mismos véase Esteve Moltó, J.E., «Los Principios Rectores sobre las empresas transnacionales y los derechos humanos en el marco de las Naciones Unidas para «proteger, respetar y remediar»: chacia la responsabilidad de las corporaciones o la complacencia institucional?», Anuario Español de Derecho Internacional, vol. 27 (2011), pp. 317 y ss.; Ovejero PueNTe, A. $M^{\text {a }}$, «Los principios Ruggie: un nuevo marco regulatorio para la gobernanza de la globalización», Actualidad civil, n. ${ }^{\circ} 1$ (2015); LETNAR CERNIC, J., «Two steps forward, one step back: the 2010 report by the UN Special Representative on Business and Human Rights», German Law fournal, vol. 11, n. ${ }^{\circ} 11$ (2010), pp.1264 y ss.; BiLCHITZ, D., «El marco Ruggie: ¿una propuesta adecuada para las obligaciones de derechos humanos de las empresas?», SUR Revista Internacional de Derechos Humanos, vol. 7, n. ${ }^{\circ} 12$ (2010), pp.209 y ss.

16 En este sentido véase Esteve MolTó, J.E., «Los Principios Rectores sobre las empresas transnacionales...», op.cit., pp. 315 y ss.

17 Marullo, $M^{\mathrm{a}}$. Ch., «Access to Justice and Forum Necessitatis in Transnational Human Rights Litigation», Papeles en el Tiempo de los Derechos, n. ${ }^{\circ} 5$ (2015), pp.1-30. 
a la justicia para las víctimas de violaciones internacionales cometidas por multinacionales. La idea central de los mismos pivota sobre tres pilares: la responsabilidad del Estado de proteger contra los abusos de derechos humanos por parte de terceros, la responsabilidad de las empresas de respetar los derechos humanos, y la necesidad para las víctimas de un acceso efectivo a los recursos ${ }^{18}$. Se cambiaba así por primera vez la forma de hacer frente a la cuestión de la protección y garantía de los derechos humanos, entendiendo que los Estados seguían siendo los principales actores de la escena internacional, pero no los únicos. De hecho, se demostraba que otros actores, como la sociedad civil y las empresas debían estar involucrados en este proceso.

\subsection{El acceso a la justicia, objetivo prioritario en los Objetivos de Desarrollo Sostenible (ODS)}

En los últimos meses nos estamos preguntando cómo los Objetivos de Desarrollo Sostenible lanzados por Naciones Unidas ${ }^{19}$ pueden contribuir a garantizar este derecho de acceso a la justicia en casos de graves violaciones perpetradas por actores no estatales. En la Nueva Agenda 2015-2030 marca$\mathrm{da}^{20}$ se evidencia como los Estados adquieren nuevos compromisos al tiempo que se garantiza la protección de los derechos humanos.

De hecho, se prioriza el acceso a la justicia entendido éste como un mecanismo eficaz para reducir las desigualdades y fomentar sociedades más justas y pacíficas ${ }^{21}$. Si con anterioridad se enfatizaba el papel de los Estados por garan-

18 Más información en: UN Human Rights Council, Report of the Special Representative of the Secretary-General on the issue of human rights and transnational corporations and other business enterprises, Protect, Respect and Remedy: a Framework for Business and Human Right, A/HRC/8/5, 2008.

19 Toda la información sobre estos 17 nuevos objetivos se puede consultar en <http://www.un.org/ sustainabledevelopment/es/>, 2015 (31 de enero de 2018).

20 Mediante la Resolución de la Asamblea General de 25 de septiembre de 2015, Transformar nuestro mundo: la Agenda 2030 para el Desarrollo Sostenible, Doc. A/RES/70/1, de 21 de octubre de 2015. Los objetivos y las metas de esta Nueva Agenda pueden consultarse en <http://www. un.org/sustainabledevelopment/es/la-agenda-de-desarrollo-sostenible/>, 2015. Oficialmente la agenda entró en vigor el 1 de enero de 2016.

21 En este sentido opera el objetivo 16. Sobre el mismo vid. en general Foundation for Democracy and Sustainable Development, <http://www.fdsd.org/ideas/sustainable-development-goal-sdg16-democratic-institutions/> y <http://www.un.org/sustainabledevelopment/es/peace-justice/> y en concreto MESA, M., «El Objetivo n. ${ }^{\circ} 16$ de Desarrollo Sostenible: paz, seguridad y gobernanza», Temas para el debate, n. ${ }^{\circ} 254-255$ (2016), pp.37 y ss. 
tizar los derechos básicos de las personas en el acceso a la justicia, con los nuevos objetivos se presenta, sin duda, una oportunidad para que a nivel nacional se puedan incluir medidas más eficaces y acciones para lograr este resultado ${ }^{22}$.

En este sentido asistimos a una transformación del concepto mismo de desarrollo sostenible ${ }^{23}$. Siguiendo a CoRTINA ${ }^{24}$, el concepto de desarrollo que se está manejando no está restringido al progreso económico, sino más bien se vincula al concepto de desarrollo humano y promoción de la paz. Por tanto, el protagonista de este proceso llega a ser el individuo. Para lograr este resultado, resulta importante involucrar en este proceso a todos los agentes que pudieran estar implicados, incluyendo al sector privado. Como explica GARCíA-MARZÁ ${ }^{25}$, tanto los Estados, sector público, como las empresas, sector privado, pueden ser entendidos como una institución capaz de fomentar o no el desarrollo humano, y, por tanto, participando en ello tienen que responsabilizarse por sus actuaciones.

Los Estados participaron en la creación de esta Agenda y se comprometieron inter alia a la protección de la dignidad, a eliminar toda forma de discriminación, a garantizar la equidad y el estado de derecho y finalmente a proteger el medio ambiente y erradicar el hambre y la pobreza, involucrando a otros actores en el proceso de desarrollo sostenible.

Para que se involucren nuevos actores en el proceso de desarrollo de las sociedades, como pueden ser las empresas, cabe estudiar las iniciativas que

22 Fifteen years ago the UN's Millennium Development Goals set out to eliminate extreme poverty. They belped bring enormous progress, but there is much left to be done. Now, with the goals set to expire in 2015 , the world is rethinking its development agenda. It's a chance to get things right. It's a chance to include a goal for justice, en Open Society Foundation, projects justice and development: the post-2015 agenda. Más Información en <http://www.ijjo.org/en/agenda/events/campaigns/justice-anddevelopment-the-post-2015-agenda>, 2015 (1 de febrero de 2018).

23 Sobre esta idea vid. Dallo, J., «Una Agenda de Desarrollo Sostenible para un nuevo ecosistema mundial», Temas para el debate, n. ${ }^{\circ}$ 254-255 (2016), pp. 41 y ss.; EnRíQUeZ SÁNCHEZ, J. Ma ${ }^{\text {., }}$ «Globalidad y solidaridad desde la perspectiva medioambiental», La Albolafia: Revista de Humanidades y Cultura, n. ${ }^{\circ} 6$ (2016), pp.133 y ss.; GuIMARÃES, R.P., «Desarrollo sustentable: ¿ todavía esperando a Godot?», Terra: revista de desarrollo local, vol. 2015, nº 1 (2015), pp.67 y ss.; MENDiZÁbal ARACAMA, $M^{\text {a }}$. T., «Nacimiento y evolución del concepto de desarrollo sostenible», en ¿Es sostenible el mundo en que vivimos?: un enfoque interdisciplinar, Universidad Pontificia Comillas, col. «Estudios Interdisciplinares», n. ${ }^{\circ} 39$ (2013), pp. 33 y ss.

24 Cortina, A., «Ética del Desarrollo: un camino hacia la paz», Sistema: Revista de ciencias sociales, n. ${ }^{\circ} 192$ (2006), pp. 3 y ss.

25 García MARZÁ, D., «¿Agentes de justicia? La responsabilidad social de las empresas como factor de desarrollo», en Pobreza y libertad. Erradicar la pobreza desde el enfoque de Amartya Sen, Tecnos, Madrid, 2009, pp. 193 y ss. 
podrían aportar mucho en la defensa y protección de las víctimas y podrían garantizar el acceso a la justicia en los casos de graves violaciones cometidas por las empresas multinacionales y con ello colmar este «ángulo muerto» del Derecho Internacional.

Como afirman Camarero Sú́rez y Zamora Cabot, al margen de los avances de los Estados en la implementación de los Principios Rectores y en los objetivos de desarrollo sostenible, la creación de un futuro Tratado Internacional sobre empresas y derechos humanos ${ }^{26}$ podría apoyar este proceso creando medidas efectivas para responsabilizar a las Empresas y garantizar foros adecuados de acceso a la justicia para las víctimas ${ }^{27}$. Además de esto, otras iniciativas podrían incidir de forma positiva en este proceso. Entre ellas podemos mencionar las propuestas sobre la creación de órganos internacionales especializados en estos temas como un Tribunal Internacional de Justicia Civil, un Tribunal Arbitral Internacional o la de ampliar el Estatuto de Roma del Tribunal Penal Internacional o una reorganización del Tribunal Europeo de Derechos Humanos para crear una sección de jueces especialistas en la evaluación de los abusos de derechos humanos por parte de las entidades no estatales $^{28}$. Mientras que del lado normativo cabría evaluar la creación de normas como un Tratado Internacional de los Pueblos para el Control de las empresas transnacionales o, la Iniciativa Popular para empresas responsables, auspiciada en el País Helvético por la Coalición Suiza de Justicia Corporativa (SCCJ) o,

26 Se está debatiendo la creación de un grupo de trabajo para la creación de normas vinculantes, propuesta avanzada por Ecuador y Sudáfrica y aprobada por la ONU el 26 de junio de 2014, que podría marcar un punto de inflexión en la lucha contra la impunidad de las empresas multinacionales. Este grupo de trabajo tendría como objetivo crear normas para que las empresas transnacionales puedan rendir cuentas por sus actividades.

27 Sobre este tema, la Federación Internacional de Derechos Humanos (FIDH) ha lanzado una plataforma para que los académicos y los profesionales en el sector de la defensa de los abusos empresariales, entre otros, puedan abrir el debate sobre el contenido y la estructura de un futuro Tratado. Más información en: <https://www.escr-net.org/news/2016/you-design-thetreaty>.

28 Sobre este aspecto véase el Informe de KHOuRY, S. y WhYTe, D., «New mechanisms of accountability for corporate violations of human rights», <https://www.liverpool.ac.uk/media/livacuk/ sociology-social-policy-and-criminology/research/New,Mechanisms,for,Accountability.pdf>, 2015 (3 de marzo de 2018). En el marco del Focus Group en el Tribunal Europeo de Derechos Humanos, el Dr. KHOURY afirmó que violations of human rights by corporations continue despite voluntary mechanisms and codes of conduct, and are often committed with impunity. At what point will the international community take responsibility and implement mechanisms that will adequately address corporate harms?. Más información en: <https://news.liverpool.ac.uk/2015/03/05/deliveringjustice-victims-corporate-human-rights-abuse/>, 2015 (14 de febrero de 2018). 
en fin, la Iniciativa de la Oficina del Alto Comisionado para los DD.HH. de las Naciones Unidas (OHCHR) para Reforzar la Responsabilidad de las empresas y el acceso a los remedios ${ }^{29}$.

\section{NORMAS DE SOFT LAW RELATIVAS A LOS ASPECTOS SOCIALES DEL DESEMPEÑO DE LAS ACTIVIDADES EMPRESARIALES}

Con el fin de colmar, por lo menos en parte, este «ángulo muerto» del derecho internacional, desde una perspectiva de Derecho Internacional Privado, cabría valorar si otras normas de soft law existentes, creadas con el fin de gestionar de forma más sostenible las grandes empresas transnacionales, pueden apoyar el proceso de creación de normas vinculantes para establecer foros alternativos para las víctimas de ilícitos internacionales y medidas más efectivas para determinar las responsabilidades civiles de los entes.

A falta de normas de hard law que puedan indicar el camino para que las empresas minimicen los riesgos y responsabilizarlas por los impactos negativos sobre los derechos humanos y sociales, han proliferado las herramientas, códigos de conductas y otras normas de soft law, que nos pueden apoyar en identificar los aspectos relevantes sobre los que se debería trabajar en los futuros años para la creación de normas vinculantes ${ }^{30}$. Un buen ejemplo es el Pacto Mundial de las Naciones Unidas ${ }^{31}$, o las Guías de la OCDE, for Multinational Enterprises, y

29 Sobre este tema, Camarero Sú́rez, Mª . V. y Zamora Cabot, F.J., «Apuntes sobre la Santa Sede y el tratado de empresas y derechos humanos», Glossae: European fournal of Legal History, n. ${ }^{\circ} 12$ (2015), pp.183 y ss.

30 Sobre este tema, véase el Prandi Chevalier, M., «Los Principios Rectores sobre las Empresas y los Derechos Humanos: significado y alcance», Tiempo de Paz, n. ${ }^{\circ} 122$ ( otoño 2016), Movimiento por la Paz, el Desarme y la Libertad, Madrid.

31 Los diez principios del Pacto Mundial de las Naciones Unidas (el Pacto Mundial): «Principio 1: Las empresas deben apoyar y respetar la protección de los derechos humanos fundamentales, reconocidos internacionalmente, dentro de su ámbito de influencia. Principio 2: Las empresas deben asegurarse de que no son cómplices en la vulneración de los derechos humanos. Principio 3: Las empresas deben apoyar la libertad de asociación y el reconocimiento efectivo del derecho a la negociación colectiva. Principio 4: Las empresas deben apoyar la eliminación de toda forma de trabajo forzoso u obligatorio. Principio 5: Las empresas deben apoyar la abolición efectiva del trabajo infantil. Principio 6: Las empresas deben apoyar la eliminación de la discriminación en materia de empleo y ocupación. Principio 7: Las empresas deberán mantener un enfoque preventivo que favorezca el medio ambiente. Principio 8: Las empresas deben fomentar las iniciativas que promuevan una mayor responsabilidad ambiental. Principio 9: Las empresas deben favorecer el desarrollo y la difusión de las tecnologías respetuosas con el medio ambiente. Principio 10: 
en tema de cadenas de suministro la Due Diligence Guidance for Responsible Supply Chains or Minerals from Conflict-Affected and High-Risk Areas de la $\mathrm{OCDE}^{32}$, que reafirman el importante papel que las empresas desarrollan en la sociedad y que por tanto deberían actuar con la debida diligencia para garantizar el respeto de los derechos humanos en todas sus actividades y a todos los niveles. Estos principios y guías se aplican a todas las empresas, con independencia de su tamaño, sector, ubicación, propietarios y estructura, a fin de obtener resultados tangibles y contribuir así a una globalización socialmente sostenible.

En el sector textil, uno de los más globalizados, y para darle más visibilidad, la OCDE ha publicado recientemente una guía titulada Due Diligence Guidance for Responsible Supply Chains in the Garment and Footwear sector ${ }^{33}$, que tiene como objetivo implementar las recomendaciones previas de la OCDE en las Cadenas de Suministro.

A nivel internacional, muchos son los estándares y protocolos de gestión que podemos encontrar, pero merece la pena destacar entre ellos algunos que resultan ser muy importantes en relación con la dimensión social de la gestión empresarial. En este sentido, por ejemplo, el ISO $26000^{34}$, norma internacional sobre responsabilidad social, que provee a los gobiernos, a las sociedades, y a las empresas, con independencia de su tamaño y de su organización, de las herramientas prácticas en las tres dimensiones del desarrollo sostenible: económica, ambiental y social.

En el tema de cadenas de suministros y en particular en el caso del sector textil, el estándar de gestión certificable más extendido a nivel mundial ha sido desarrollado por el Social Accountability Internacional (SAI), concretada en la $\mathrm{SA} 8000^{35}$. De cara a obtener la certificación, esta norma establece

Las empresas deben trabajar contra la corrupción en todas sus formas, incluidas la extorsión y el soborno». Más información en: <http://www.pactomundial.org/wp-content/uploads/2015/04/ ppios-laborales-del-PactoMundial-guia-para-empresas.pdf>, 2010 (febrero 2018).

32 OECD Due Diligence Guidance for Responsible Supply Chains of Minerals from Conflict-Affected and High-Risk Areas, 2012 OECD Guidelines for Multinational Enterprises, 2011, más información <http://www.oecd.org/corporate/mne/mining.htm>.

33 Más información en <http://www.comunicarseweb.com.ar/sites/default/files/oecd-due-diligence-guidance-garment-footwear_0.pdf>.

34 Más información en <http://www.iso.org/iso/iso_26000_project_overview-es.pdf>.

35 La SA 8000 es una norma certificable de aplicación voluntaria, es una norma de mínimos, creada para que se respeten las condiciones establecidas en la Declaración Universal de los Derechos Humanos de la ONU, la Convención Internacional de los Derechos del Niño y los convenios de carácter internacional que promueve la Organización Internacional del Trabajo. Más información sobre el SA8000 Standard, en <http://www.sa-intl.org/index.cfm?fuseaction=page. viewpage\&pageid=1689>. 
requisitos de responsabilidad social y pautas transparentes, medibles y verificables, del desempeño de las actividades empresariales: prohíbe el trabajo infantil y el trabajo forzoso; prohíbe la discriminación, el castigo corporal o la coerción física o mental de los trabajadores, promueve el establecimiento de un ambiente de trabajo seguro y saludable mediante la seguridad y la salud de los trabajadores, protege los derechos de los trabajadores de formar sindicatos o de afiliarse a ellos y establece pautas para el horario de trabajo y la remuneración.

En 2017 se ha lanzado la ISO 20400³6, Sustainable procurement-Guidance, mostrándose como un primer estándar para la sustainable procurement, pretendiendo ayudar a las organizaciones a desarrollar e implementar políticas y prácticas de compras sostenibles. Este instrumento ha sido creado con el fin de unificar la materia en torno a los principios de sostenibilidad, rendición de cuentas, transparencia, respeto de los derechos humanos y comportamiento ético.

Otro estándar que merece ser mencionado y que puede ser útil en este proceso, rediseñando también los alcances de la evaluación de la gestión empresarial en términos de derechos humanos, es el relativo al desempeño de sostenibilidad social y ambiental de la Corporación Financiera Internacional (IFC) del año 2006 actualizado en el año 2012 37 , que establece directrices sobre el desempeño social y medioambiental ayudando a reducir la pobreza y a mejorar la vida de los pueblos. En su versión actualizada, esas directrices hacen referencia directa a los derechos humanos:

La IFC reconoce la responsabilidad de las empresas de respetar los derechos humanos, independientemente de las obligaciones del Estado de respetarlos, protegerlos y hacerlos efectivos. Esta responsabilidad significa evitar infringir los derechos humanos de los demás y abordar los impactos adversos sobre los derechos humanos que puedan causar dichas empresas o a los que estas puedan contribuir. [...] Las Normas de Desempeño de la IFC promueven esta responsabilidad del sector privado.

36 Más información en <https://www.iso.org/news/Ref2178.html?utm_medium= email\&utm _campaign= ISO\%20Newsletter\%20May\%202017\&utm_content=ISO\%20Newsletter\%20 May\%202017+CID_6a831f21972886cf39d25132f5b6173e\&utm_source=Email\%20marketing\%20software\&utm_term=Read\%20more >.

37 Más información sobre la Política de la Corporación Financiera Internacional sobre Sostenibilidad Ambiental y Social en <http://www.ifc.org/wps/wcm/connect/d6f1e00049a79ce5b9c2fba8c6a8312a/SP_Spanish_2012.pdf?MOD=AJPERES>, 2012 (14 diciembre 2017). 
Son, en fin, un pequeño elenco de posibilidades que, de una manera dispersa, silenciosa, pero continuada, encontramos salpicando la normativa vigente, que marcan el camino para que las empresas se comporten en el mercado con el máximo respeto a los derechos humanos.

\section{LAS INICIATIVAS ESTATALES Y REGIONALES QUE INCORPORAN LAS NOVEDADES INTRODUCIDAS POR LAS NORMAS DE SOFT LAW}

Todas estas normas de soft law ponen el énfasis sobre la necesidad de hacer que las empresas transnacionales sean más transparentes en sus actividades también en términos de derechos humanos y laborales. Trasparencia en las actividades directas de las empresas, pero también trasparencia en los mecanismos de supervisión de las actividades indirectas o desarrolladas por otras empresas en la misma cadena de suministro.

Sobre este aspecto, un paso muy importante en esta dirección ha sido la Directiva 2014/95/UE del Parlamento Europeo y del Consejo, que se aprobó el 22 de octubre de $2014^{38}$. Esta norma establece pautas para la divulgación de información no financiera de grandes empresas, las que cuenten con más de 500 empleados, y ha establecido una obligación clara de éstas en la presentación de un informe anual que, entre otras cosas, detalle su gestión en relación con el respeto de los derechos humanos (art. 29 bis). El Gobierno español acaba de transponer esta directiva mediante el correspondiente Real-Decreto Ley 18/2017, modificando la Ley de sociedades de capital y el Código de comercio ${ }^{39}$.

Siempre a nivel nacional asistimos a la incorporación de normas similares sobre transparencia, por ejemplo, en los Planes Nacionales sobre empresas y derechos humanos, como el reciente Plan de Empresa y Derechos Humanos de 2017

38 En relación con esta Directiva véase Fernández GazTEA, J. y MuÑoz FernándeZ, A., «Comply or explain» in the EU, or the new human rights reporting obligation: an analysis of Directive 2014/95/EU», Cuadernos de Derecho Transnacional, vol. 9, n. ${ }^{\circ} 1$ (marzo 2017), pp. 285 y ss., DOI: <https://doi.org/10.20318/cdt.2017.3622, 2017> (abril 2018).

39 Real Decreto-ley 18/2017, de 24 de noviembre, por el que se modifican el Código de Comercio, el texto refundido de la Ley de Sociedades de Capital aprobado por el Real Decreto Legislativo 1/2010, de 2 de julio, y la Ley 22/2015, de 20 de julio, de Auditoría de Cuentas, en materia de información no financiera $y$ diversidad, BOE Núm. 287, de 25 de noviembre de 2017.

40 El plan fue publicado en el BOE n. ${ }^{\circ} 222$, de 14 de septiembre de 2017, mediante Resolución de 1 de septiembre de 2017, de la Secretaría de Estado de Asuntos Exteriores, por la que publica el Plan de Acción Nacional de Empresas y Derechos Humanos. 
auspiciado con mucho ímpetu por España, aunque con un futuro un tanto incierto si tenemos en cuenta el tiempo que se ha tardado en aprobarlo. Es necesario hacer hincapié en el hecho de que para que estas iniciativas no queden vacías de contenido, los Estados deberían valorar la posibilidad de incluir medidas directas para responsabilizar y sancionar a las empresas transnacionales cuando falte supervisión y control sobre sus cadenas de suministro, lo que puede devenir en que se generen graves violaciones de derechos humanos y laborales en las mismas.

Cabe subrayar que hay otras iniciativas legislativas nacionales, con independencia de los planes nacionales, que actualmente están dando visibilidad a las normas de armonización de la OCDE y a los Principios Rectores para dar efectividad a la tutela de los derechos humanos y responsabilizar a las empresas. Un ejemplo es la implementación el Modern Slavery Act de $2015^{41}$ que ha sido enmendado desde la óptica de incorporar y dar efectividad a los marcos internacionales existentes ${ }^{42}$. Recientemente también la Asamblea Nacional Francesa ha adoptado la Proposition de Loi relative au devoir de vigilance des sociétés mères et des entreprises donneuses d'ordre ${ }^{43}$ que incorpora los avances de las normas de armonización en estas materias y que establece obligaciones para las empresas matrices francesas. En particular se prevé que las empresas deberán identificar y prevenir los impactos negativos en los derechos humanos, la salud y el medioambiente resultantes de sus actividades y de las actividades de las empresas que controlan, de subcontratistas y de proveedores. Las empresas sujetas a esta norma, entre otras medidas, deberán establecer y aplicar efectivamente un plan de vigilancia que deberá cubrir las actividades

41 «The Modern Slavery Act will give law enforcement the tools to fight modern slavery, ensure perpetrators can receive suitably severe punishments for these appalling crimes and enhance support and protection for victims». Más información en <http://www.legislation.gov.uk/ukp$\mathrm{ga} / 2015 / 30 /$ contents/enacted $>$.

42 Más información en <http://www.lexology.com/library/detail.aspx?g=86cac3c9-e23b-4f1c9268-f7f4cadae4ad\&utm_source=Lexology+Daily+Newsfeed\&utm_medium=HTML+email++Body+-+General+section\&utm_campaign=Lexology+subscriber+daily+feed\&utm_content=L exology+Daily+Newsfeed+2017-02-24\&utm_term>, 2017 (diciembre 2017).

43 Assemblée Nationale Constitution du 4 octobre 1958 Quatorzième Législature Session Ordinaire de 2016-2017, 21 février 2017. Proposition de Loi relative au devoir de vigilance des sociétés mères et des entreprises donneuses d'ordre (Texte définitif). Más información en <http:// www.assemblee-nationale.fr/14/pdf/ta/ta0924.pdf>, 2017 (diciembre 2017). Para un análisis de esta Propositions de Loi remitimos a MOUgeOLLE, P., «Sur la conformité constitutionnelle de la proposition de loi relative au devoir de vigilance des sociétés mères et des entreprises donneuses d'ordre; Responsabilité juridique des entreprises», Revue des droits de l'homme [En ligne], Actualités Droits-Libertés, mis en ligne le 15 février 2017, <http://revdh.revues.org/2970>, 2017 (diciembre 2017). 
de la empresa matriz y de las otras empresas bajo su control, así como los proveedores y subcontratistas con los que la empresa matriz o cualquiera de sus filiales han establecido una relación comercial. Por último, se establecen sanciones pecuniarias en caso de incumplimiento de esa obligación por parte de las empresas matrices.

Estas propuestas de normas prevén que, para la redacción del plan de vigilancia, la empresa transnacional utilizará las herramientas existentes a nivel internacional.

\subsection{La solución californiana para supervisar las cadenas de suministros}

El vacío legal a nivel internacional de normas vinculantes que hemos apuntado en los apartados precedentes, ha fomentado la proliferación de mecanismos y reglas de conducta, códigos y análogas iniciativas desde el orden empresarial para la elaboración memorias de sostenibilidad o informes de responsabilidad social ${ }^{44}$. No obstante, estas nuevas herramientas, que pretenden institucionalizar un modelo de negocio socialmente responsable, no prevén casi ningún tipo de mecanismo de sanción en caso de incumplimiento ${ }^{45}$ y obviamente, no garantizan el acceso a la justicia de las víctimas de las graves violaciones perpetradas por empresas trasnacionales.

Es por ello por lo que la conclusión más obvia a la que podemos llegar es que la clave de la nueva lucha contra estas prácticas es la colaboración públicoprivada. Los avances en el seguimiento y vigilancia de la cadena de suministro

44 La responsabilidad social de la empresa (RSE) es el reflejo de la manera en que las empresas toman en consideración las repercusiones que tienen sus actividades sobre la sociedad, y en la que afirman los principios y valores por los que se rigen, tanto en sus propios métodos y procesos internos como en su relación con los demás actores. La gestión responsable de la empresa implica que ésta adecue los intereses del negocio con las expectativas que de ella tiene la comunidad. La RSE es una iniciativa de carácter voluntario y que sólo depende de la empresa, y se refiere a actividades que se considera rebasan el mero cumplimiento de la legislación (Iniciativa InFocus sobre responsabilidad social de la empresa, Consejo de Administración, 295 . reunión, Ginebra, 2006, más información en <http://www.ilo.org/public/libdoc/ilo/GB/295/GB.295_MNE_2_1_span. pdf, 2006 (1 de febrero de 2018)).

45 De hecho, la crítica más frecuente es el débil régimen de sanciones en caso de incumplimiento. En la mayoría de casos el principio que se aplica es del comply or explain, en base al cual una empresa que no cumple con las reglas establecidas tendrá que motivar el porqué de tal inobservancia. Como consecuencia, muchas empresas sostienen sus decisiones de no estar obligados en cumplir con una determinada norma por razones de privacy o de costes elevados. 
y de la responsabilidad social corporativa están conduciendo a una valiosa colaboración entre los gobiernos y las principales empresas ${ }^{46}$.

Coincidiendo con los esfuerzos iniciados por Naciones Unidas y a los que nos hemos referido con anterioridad, los Estados Unidos adoptaron el año 2000 una importante Ley Federal para luchar contra la trata de personas: la Federal Victims of Trafficking and Violence Protection Act of 2000 ${ }^{47}$. Paralelamente se había creado la California Alliance to Combat Trafficking and Slavery Task Force (CA ACTS Task Force), que se encargaba de recabar información y elaborar informes sobre la respuesta que daba California frente a la trata de personas para el Gobernador, el Fiscal General y el Legislador. En octubre de 2007, el Departamento de Justicia de California publicó el Informe final del CA ACTS Task Force ${ }^{48}$, que contenía una lista de resultados y recomendaciones para combatir la trata de personas. El informe invocaba la responsabilidad moral de California para ejercer el liderazgo, a través de su administración y de sus empresas, en la tarea de promover prácticas de trabajo justas y humanas en las cadenas de suministro. Esta responsabilidad moral que se estaba demandado, requeriría que la comunidad empresarial hiciera uso de su influencia económica para prevenir de forma proactiva el trabajo forzoso en las prácticas de abuso de los derechos humanos dentro de su cadena de suministro, además de favorecer la concienciación general entre los californianos ${ }^{49}$.

46 Department of State of the United States of America, Trafficking in Persons Report, fune 2012, p. 7.

47 Public Law 106-386, October 28, 2000, 114 STAT. 1464-1548, $106^{\text {th }}$ Congress, An Act To combat trafficking in persons, especially into the sex trade, slavery, and involuntary servitude, to reauthorize certain Federal programs to prevent violence against women, and for other purposes, que se puede consultar en <http://www.state.gov/documents/organization/10492.pdf>, 2000 (2 de marzo de 2018).

48 Final Report of the California Alliance to Combat Trafficking and Slavery Task Force. October 2007, Administered by the California Attorney General's Office. Crime and Violence Prevention Center, que se puede consultar en <http://oag.ca.gov/sites/all/files/pdfs/publications/Human_Trafficking_ Final_Report.pdf>, 2007 (2 de marzo de 2018).

49 Koekkoek, M.; Marx, A. y Wouters, J., «Monitoring Forced Labour and Slavery in Global Supply Chains: The Case of the California Act on Transparency in Supply Chains», Global Policy, vol. 8, issue 4, Version of Record online: 29 nov 2017.

$<$ https://apps.webofknowledge.com/full_record.do?product=UA\&search_mode=MarkedList\&qid $=1 \&$ SID $=$ D3sAxGzICtSlucD8G5y\&page $=1 \&$ doc $=7 \&$ colName=WOS \& cacheurlFrom RightClick=no», 2017 (10 marzo de 2018); GreEN, B.T. y PuRVIS, J.G., «Corporate supply chain transparency: California's seminal attempt to discourage forced labour», The International Fournal of Human Rights, vol. 20, issue 1, <https://doi.org/10.1080/13642987.2015.1039318>, 2016 (febrero 2018). 
El creciente interés por parte de las mismas empresas en la proliferación de normas de autorregulación se podría leer desde la perspectiva de que dichas corporaciones quieran evitar los problemas derivados de graves violaciones o aprovechar sus buenas prácticas como ventaja competitiva ante un consumidor preocupado y consciente, que valora y recompensa a la empresa que así se comporta.

En ambos casos, como también en los códigos de conducta internos, se deja en manos privadas la tarea de proteger los derechos humanos.

Justamente en ese punto se apoya la solución prevista por el legislador de California en la Transparency in Supply Chains Act, que parte de la confianza de que el consumidor premiará o castigará a las grandes empresas que realicen actividades comerciales en California en función de la preocupación de éstas por el respeto de los derechos humanos en su cadena de suministro. En 2010 este Estado incorporaba a su repertorio legislativo la Ley de California sobre Transparencia en la Cadena de Suministros (en adelante CTSC) $)^{50}$, que tenía como propósito limitar las posibles violaciones de derechos humanos, principalmente sobre la trata de seres humanos, potencialmente ejercidas por empresas multinacionales a través de sus cadenas de suministros.

La propia norma reconocía que $[A]$ s a result of the criminal natures of slavery and human trafficking, these crimes are often bidden from view and are difficult to uncover and track. La lucha pues se dirigía en esta norma hacia la erradicación por un lado de la esclavitud (slavery) y de otra del tráfico de seres huma-

50 Nos referimos a la Ley de California sobre Transparencia en la Cadena de Suministros, sobre tráfico de seres humanos (Senate Bill n. ${ }^{\circ}$ 657. CHAPTER 556. An act to add Section 1714.43 to the Civil Code, and to add Section 19547.5 to the Revenue and Taxation Code, relating to human trafficking. [Approved by Governor September 30, 2010. Filed with Secretary of State September 30, 2010.]). El texto completo de la ley se puede consultar en <http://www.leginfo.ca.gov/pub/0910/bill/sen/sb_0651-0700/sb_657_bill_20100930_chaptered.pdf>, 2010. La parte de la ley que se integra en el Código Civil lo hace en su División referida a las obligaciones, y en concreto a las obligaciones que se derivan de la ley, pasando a constituir el $\$ 1714.43$ (2012) del Código Civil. Estos preceptos establecen qué compañías son las obligadas por la ley y en qué consisten sus obligaciones.

Los apartados de la ley que pasan a formar parte del Código de los Impuestos lo hacen en el marco de la administración del Franchise and Income Tax Laws, y más en concreto en el artículo referido a la revelación de datos por parte de quienes administran el impuesto. El resultado de este cambio es la introducción de una excepción al deber de no revelar la información que el departamento que administra el impuesto posee como consecuencia de la tarea que realiza. Por mandato del nuevo texto legal, el Franchise Tax Board deberá poner a disposición del Fiscal General del Estado la lista de las compañías que deben cumplir con esta ley. 
nos (buman trafficking) ${ }^{51}$, sumándose de este modo a las políticas estatales para «educar a los consumidores sobre cómo adquirir unos bienes producidos por empresas que gestionan de manera responsable sus cadenas de suministro» $(\text { art. } 2[\mathrm{j}])^{52}$.

Con la CTCS no se buscaba tanto un medio para obtener reparación por los daños causados, como prevenir que éstos se produjeran. Obligando a las multinacionales a divulgar sus acciones a favor de la erradicación de las violaciones de derechos humanos no sólo dentro de la propia empresa, sino también en su cadena de suministro, la CTCS se apoyaba en la confianza de que el consumidor premiaría o castigaría a aquellas empresas que realizaran actividades comerciales en función de la preocupación de éstas por el respeto de los derechos humanos en su cadena de suministro ${ }^{53}$.

Cabe afirmar desde este planteamiento, que se dejaba en manos privadas la tarea de proteger los derechos humanos, lo cual dota de sentido la afirmación de que with every dollar that we spend, we vote for the world we want ${ }^{54}$. La virtud de la ley californiana es que empresas y consumidores juegan un papel

51 Sobre el alcance y significado de estos términos vid. MuÑOZ, A., «Nuevas iniciativas con la trata de personas: la implicación de todos los actores (el papel de los particulares)», Cuadernos de Derecho Transnacional, vol. 4, n. 2 (octubre 2012), pp. 342 y ss., en concreto p. 346 y DuNNE. J. L., «Hijacked: how efforts to redefine the international definition of human trafficking threaten its purpose», Willamette Law Review, n. ${ }^{\circ} 48$ (2012), pp. 403 y ss.

52 SEC. 2. (j) It is the policy of this state to ensure large retailers and manufacturers provide consumers with information regarding their efforts to eradicate slavery and buman trafficking from their supply chains, to educate consumers on how to purchase goods produced by companies that responsibly manage their supply chains, and, thereby, to improve the lives of victims of slavery and human trafficking.

53 Esta solución presenta ciertas analogías con los etiquetados de productos que se emplean para garantizar al consumidor que lo que compran ha sido elaborado respetando unos estándares, ya sean ecológicos, ya sean de observancia de los derechos humanos, etc. Aunque tienen en común el dejar la decisión final en manos del consumidor, a diferencia de lo que ocurre con la ley californiana, el etiquetado es, por lo general, voluntario para las empresas que quieren beneficiarse de su actuar responsable. En este sentido vid. LiUbiCIC, R. J., «Corporate Codes of Conduct and Product Labeling Schemes: The Limits and Possibilities of Promoting International Labor Rights through Private Initiatives», Law and Policy in International Business, vol. 30, issue 1 (1998), pp. 111 y ss.; KarbowsKi, J. M., «Human Rights Labeling: A WTO Compliant Strategy to Harness the Power of Consumer Preference» (2008). Student Prize Papers, Paper 36, <http:// digitalcommons.law.yale.edu/ylsspps_papers/36>, 2008 (14 de enero 2018).

54 Aunque la frase se le atribuye a OSGOOD, en el Informe Corporate Compliance with the California Transparency in Supply Chains Act: Anti-Slavery Performance in 2016, Chris N. Bayer \& Jesse H. Hudson, March 7, 2017, que se puede consultar en <http://www.ipoint-systems.com/ fileadmin/media/resources/CA-TISCA.v.25_S.pdf>, 2017 (14 de enero 2018), lo cierto es que la autoría de la misma o versiones de ella está indeterminada. En cualquier caso, ilustra muy acertadamente el espíritu de la CTSC. 
decisivo para contribuir en su permanente relación a la erradicación de estas prácticas degradantes de forma global. La ley plantea exclusivamente sanciones a las empresas por el incumplimiento de la publicación de información empresarial, sin entrar a valorar lo que esta información contenga. Esto es, si la empresa no ha realizado ninguna acción de control o vigilancia sobre las acciones de su cadena de suministro o sobre sus propias acciones, basta con publicar dicha inactividad para quedar exonerada de la sanción prevista por la ley. Y ello, porque el legislador cuenta con que sea el consumidor el que verdaderamente garantice el éxito de la ley, penalizando a aquellas compañías que no se esfuercen por hacer frente a esta lacra social, y premiando a aquellas que se tomen en serio la tarea de eliminar estas prácticas contrarias a la dignidad humana.

Fue en enero de 2012 cuando la ley entró en vigor, lo que supuso que desde ese momento las empresas que reunieran los requisitos establecidos por la ley deberían cumplir con la obligación de publicar las acciones o esfuerzos por controlar que quienes formaban parte de su cadena de suministro no incurrían en trata de personas ni en prácticas esclavistas. Un aspecto importante que fue modificado en una de las últimas enmiendas, era el relativo al alcance de las obligaciones de las compañías. Si durante la tramitación se hablaba de require retail sellers and manufacturers doing business in the state to develop, maintain, and disclose their efforts to eradicate slavery and buman trafficking from their supply chains, as specified, finalmente la obligación se limitó a la divulgación de las acciones que se llevaran a cabo, y no propiamente a las emprendidas.

La CTCS tiene algunos aspectos de extraterritorialidad que conviene resaltar, aunque sea someramente. En primer lugar, la ley de California precisa que la compañía tenga una vinculación con el territorio, aunque generalmente estaremos hablando de empresas que extienden sus actividades más allá de dichas fronteras. Estas empresas contarán además con proveedores fuera del Estado y del país, por lo que la ley incentiva la realización de unas conductas que probablemente deberán realizarse fuera de California. Del mismo modo la información a divulgar se referirá muchas veces a actuaciones llevadas a cabo en el extranjero. Otro factor de extraterritorialidad es la sanción voluntaria del consumidor. Dado que la información se debe publicar, en principio, en la página web de la compañía transnacional, cualquier consumidor o inversor podrá tener acceso a ella y podrá adoptar medidas de premio o castigo, con independencia de dónde se encuentre el consumidor y sobre dónde se han producido (o dejado de producir) las mencionadas prácticas. De esta manera, el estado de California, sirviéndose de la posibilidad de exigir una conducta 
-publicación de una información- a las empresas que tienen un concreto vínculo con el país y cuyos datos conoce por motivos tributarios, puede conseguir mitigar unas prácticas que en la mayoría de los casos se realizan fuera de sus fronteras.

Se establece por lo tanto un triple plano de control potencial: el que las multinacionales realicen sobre sus proveedores; el que debe llevar a cabo el Attorney General exigiendo que se publique la información sobre esas medidas; y finalmente, el que adoptará el consumidor dependiendo de su sensibilidad hacia estas cuestiones. Por decirlo con otras palabras, el éxito de esta ley depende de las empresas (que por las dimensiones que detalla la ley serán muchas veces multinacionales) -que han de auditar la actuación de su cadena de proveedores-; de la Fiscalía General del Estado -que debe controlar bajo sanción que las multinacionales cumplan esa obligación o, más bien, que hagan público si hacen o no esa auditoría-; y finalmente, del consumidor que será quien dote de fuerza coercitiva a la ley.

Aunque el destinatario principal de las leyes son claramente las empresas de ciertas dimensiones que realicen actividades comerciales en California, hay también otros afectados por las leyes de forma más o menos indirecta. Nos referimos por un lado al Franchise Tax Board, órgano encargado de administrar el impuesto sobre sociedades, que tendrá que facilitar al Attorney General el listado de las empresas que deben cumplir con la ley. Y consecuentemente al Attorney General, que debe comprobar que las empresas obligadas publiquen la información que exige la ley. Son pues estos dos únicos órganos del estado los que tienen que intervenir en la puesta en marcha de la ley californiana.

Como ya se ha señalado, la CTCS se inserta en dos diferentes textos normativos: una sección de la ley de California se ha encuadrado en el Civil Code de California y otra en el Revenue and Taxation Code. Esta última se añade a la parte referente al Corporation Franchise Tax, en concreto en el capítulo dedicado a administración de dicho impuesto y más específicamente en el artículo que atañe a la divulgación de información. Conforme a dicho artículo, en principio, la revelación de información por parte de quienes administran el impuesto constituye un delito. No obstante, existen ciertas excepciones, entre las que se encuentra la incorporada por la CTCS.

La CTCS establece que el Franchise Tax Board -órgano encargado de administrar y hacer cumplir el impuesto- pondrá a disposición de la fiscalía la lista de minoristas y fabricantes a los que se les exige publicar las acciones para erradicar la esclavitud y la trata de personas. La lista se presentará anualmente al Attorney General y la información que debe figurar en la lista es el nombre 
de los vendedores minoristas y fabricantes obligados y su número de identificación de California. Con esa lista, el Attorney General podrá comprobar si las empresas enumeradas han cumplido con la obligación de publicar la información exigida por la ley.

Hay que subrayar una vez más que la ley no obliga a las empresas a adoptar medida de control alguna. Simplemente obliga a publicar la información sobre lo que se hace (o no se hace) para controlar que no se den casos de trata de seres humanos en su cadena de suministro. Por lo tanto, la labor del Attorney General es comprobar si las empresas obligadas han cumplido con este deber.

No obstante, como hemos señalado anteriormente, los destinatarios principales de la ley de California son las empresas. Pese a que en un primer momento del iter de la ley de California se pretendía imponer obligaciones concretas de llevar a cabo conductas encaminadas a la lucha contra la trata de personas y la esclavitud, finalmente sólo se estableció una obligación de publicar información sobre lo que se hace en esta materia. Por lo tanto, la exigencia de llevar a cabo esas acciones sólo viene impuesta a través de una coacción indirecta: podemos emprender esas acciones o no, pero tenemos que dar a conocer al consumidor si las hacemos o no.

Una vez aclarado que el deber que imponen estas leyes es de publicar información, queda saber cuál debe ser el contenido de dicha información. Los fabricantes y los comerciantes minoristas que realicen actividades comerciales en el estado de California en los términos descritos deben rendir cuentas sobre sus acciones para controlar que en su cadena de suministro no se incurre en prácticas esclavistas ni en otros casos de trata de personas.

En concreto, deberán manifestar:

1) Si participa en la verificación de las cadenas de suministro de los productos para evaluar y abordar riesgos de trata de personas y esclavitud. Si la verificación no se llevó a cabo por un tercero deberá indicarse en la información que se publique.

2) Si lleva a cabo auditorías de los proveedores para evaluar si cumplen con los estándares de la empresa sobre trata de personas y esclavitud en las cadenas de suministro. Si la verificación no fue hecha mediante auditoría independiente y sin previo aviso deberá indicarse en la información que se publique.

3) Si exige que los proveedores directos certifiquen que los materiales incorporados en producto cumplen con la legislación sobre esclavitud y trata de personas del país o países en los que están realizando actividades comerciales. 
4) Si posee normas internas de rendición de cuentas y procedimientos para los empleados o contratistas que no cumplen con las normas de empresa con respecto a la esclavitud y la trata de personas.

5) Si dota a los empleados y gestores de la empresa, que tienen la responsabilidad directa de la gestión de la cadena de suministro, de la capacitación sobre la trata de personas y la esclavitud, particularmente con respecto a la mitigación de riesgos dentro de las cadenas de suministro de productos.

La obligación impuesta por estas leyes consiste en anunciar esta divulgación en la página web de la empresa con un link visible y fácil de entender que enlace con la información requerida situado en la página de inicio de la empresa. En el caso de que la empresa carezca de sitio web, deberá estar preparada para poner esta información por escrito a disposición del consumidor que se lo solicite en un plazo de 30 días $^{55}$.

Los efectos de la ley afectarán también a todos aquellos que componen la cadena de suministro de la que participan las empresas obligadas por las leyes analizadas. Si éstas quieren publicar un informe que favorezca su imagen, las empresas de la cadena de suministro serán objeto de un mayor control y serán sometidas a unos estándares en materia de trata de personas. En concreto, la ley californiana se refiere a la cadena directa de proveedores de bienes materiales ofrecidos para la venta.

De alguna manera, los consumidores, los inversores, otras empresas, están llamados a jugar un papel decisivo. De su diligencia para informarse y de su sensibilidad hacia los derechos humanos dependerá el éxito de la ley, pues ellos son los que deben premiar o castigar a las empresas en función de los informes que publiquen. No obstante, las leyes en ningún momento se refieren a ellos como sujetos de obligación alguna. Sí se advierte, sin embargo, en la exposición de motivos, que los consumidores, los inversores y las empresas promueven o sancionan estos crímenes al comprar bienes y productos que han sido «manchados» en la cadena de suministro.

El objetivo de la ley es que los grandes comercios y fabricantes faciliten información a los consumidores sobre sus esfuerzos por erradicar la trata de

55 Con esta última alternativa se da solución a la objeción de la California Grocers Association frente al primer texto en el que sólo se mencionaba la opción de la divulgación en la web. Dicha asociación advertía que muchas tiendas de alimentación carecían de página web y no podrían cumplir con la disposición de la ley. 
personas y la esclavitud en su cadena de suministro, para educar al consumidor sobre cómo comprar bienes producidos por empresas que cuidan de su cadena de suministro, y mejorar así la vida de las víctimas de la esclavitud y de la trata de personas.

Sin embargo, como ya se ha dicho, el principal obligado por la ley es la empresa que reúna las condiciones señaladas por la ley. ¿A qué empresas puede obligar el estado de California a cumplir ese deber de transparencia? ¿qué vínculo tienen que tener con el Estado?

La ley establece así que la obligación alcanza, siempre que concurran otras circunstancias referentes a su volumen de negocios, a los vendedores al por menor y fabricantes que realicen actividades comerciales en su territorio (doing business in this state). Teniendo en cuenta el criterio que sigue la ley, será fundamental determinar qué entender por doing business in this state. Para ello se nos remite a la Section 23101 del Revenue and Taxation Code. Según dicha norma realizan actividades comerciales quienes participan activamente en cualquier transacción con el propósito de lucro o beneficio pecuniario ${ }^{56}$.

Pero la obligación que establece la CTCS no afecta a todos los fabricantes y comerciantes minoristas que lleven a cabo actividades comerciales en California, sino solamente a aquellos que tengan un volumen de ingresos importante. En concreto, el mandato legal alcanzaba únicamente a las empresas con unos ingresos brutos mundiales superiores a 100.000.000 de dólares ${ }^{57}$.

Como puede apreciarse, la ley se apoya en gran medida en el sector privado para luchar contra la trata de personas. Ello supone un importante cambio

56 Aunque según el mismo precepto y, a partir del 1 de enero 2011, realizan actividades comerciales en California en un concreto año contributivo quienes cumplan alguna de las siguientes condiciones:
a) tener el domicilio a efectos comerciales en el estado.
b) tener unas ventas superiores a 500.000 dólares en el estado o tener el 25\% de las ventas de la empresa en el estado.
c) los inmuebles y bienes tangibles en California superen los 50.000 dólares o supongan al me- nos el $25 \%$ de sus bienes totales.
d) las remuneraciones pagadas a sus empleados en California excedan los 50.000 dólares o el $25 \%$ del total en todo el mundo.
57 Durante la elaboración de la ley se modificó la cifra de ingresos para las empresas, ya que se preveía en los primeros borradores la cifra de 2.000 .000 de dólares en ventas anuales. La razón de este sustancial cambio pudo ser la oposición de la asociación la California Grocers Association, que consideraban que para este tipo de comerciantes sería una carga excesiva, y muchas veces de imposible cumplimiento, el llevar a cabo un control que incluiría a proveedores que muchas veces estarán situados fuera de las fronteras de California.


en relación con los mecanismos empleados en el pasado, en los que el peso principal de la acción represiva recaía sobre el poder público. Por eso algunos autores han reflexionado sobre la justificación para establecer esta imposición sobre las empresas. En este sentido se ha argumentado que el sector privado, incluyendo negocios legítimos, obtienen beneficios, directa o indirectamente de la trata de personas. Se ha dicho también que el sector privado se encuentra en una posición única para prevenir algunas de estas prácticas contrarias a los derechos humanos. De hecho, son muchas las grandes empresas que ya vienen ejerciendo cierto control sobre sus proveedores, aunque normalmente con otros fines tales como la consecución de una mayor eficiencia y productividad. Por otro lado, se ha señalado que los costes que supone este control son más fácilmente asumibles hoy en día por las grandes multinacionales que por el poder público.

Si tenemos que hacer un balance de lo que ha supuesto la CTCS, lo cierto es que ha hecho que numerosas empresas estén cumpliendo con el mandato impuesto de información, aunque se pone de manifiesto en numerosas ocasiones que los esfuerzos gubernamentales para poner de relieve el trabajo forzoso han producido resultados mixtos. La CTCS no ha tenido un gran impacto, según un informe reciente del grupo sin fines de lucro Development Internatio$n a l^{58}$, aunque si tenemos en cuenta las resoluciones judiciales hemos de afirmar algún avance en la materia.

Planteada como una ley que involucra al consumidor como garante de la protección de los derechos humanos, ¿̇puede interpretarse como que la ley legitima al consumidor a interponer algún tipo de acción contra las empresas que no controlen a sus cadenas de suministros?

En este sentido, podríamos pensar en un consumidor que compra un producto confiando en la información publicada por una empresa sobre los importantes esfuerzos que realiza para luchar contra la esclavitud en su cadena de suministros. Si posteriormente se demostrase que en la cadena de esa empresa se producen violaciones de los derechos humanos ¿podría el consumidor exigir algún tipo de responsabilidad a la empresa? ¿podría el consumidor exigir a la empresa que advierta en sus productos que han sido elaborados de esta manera?

$58 \mathrm{El}$ informe del 2016 puede consultarse en <http://www.ipoint-systems.com/fileadmin/media/ resources/CA-TISCA.v.25_S.pdf>, 2017 (febrero 2018). 


\subsection{Los fallos del legislador estadounidense y las respuestas jurisprudenciales}

Para responder a los interrogantes que acabamos de plantear nos serviremos del asunto Nestlé. Este ha sido el pronunciamiento judicial más importante en relación con la CTSC y lo cierto es que ha sido también el más sorprendente, al estimar el Tribunal del Distrito Central de California la petición de Nestlé para que se rechazara la demanda presentada contra ella por Melanie Barber y otros (acción colectiva de consumidores). Los demandantes alegaban que un producto alimenticio para gatos comercializado por Nestlé, «Fancy Feast», contenía pescado capturado en aguas de Tailandia e Indonesia. En esa zona Nestlé es socio de Thai Union Frozen Products que cuenta con varios proveedores que son grandes embarcaciones con refrigeradores que a su vez reciben pescado de numerosos pequeños botes de pesca. Tanto Nestlé como Thai Union son conscientes de que en alguna de esas pequeñas embarcaciones se dan situaciones de trabajos forzados, aunque consideran imposible conocer su gravedad.

Tras comprar el producto y, posteriormente, ser conocedores de estos hechos, los demandantes interpusieron una acción contra Nestlé por entender que ésta había violado la California Unfair Competition Law (UCL), la California Consumers Legal Remedies Act (CLRA) y la California False Advertising Law $(F A L)^{59}$. Sostenían, adicionalmente, que Nestlé estaba obligada a informar a los consumidores de que una parte de sus productos de comida para gatos podría contener pescado obtenido con trabajo forzado. Como consumidores, consideraban que tenían derecho a saber que el producto que estaban adquiriendo se había fabricado, aunque fuera en parte, con violación de derechos humanos.

La sorpresa, jurídicamente hablando, fue que la norma jurídica principal a la que Nestlé recurrió para solicitar la desestimación de la demanda fue, curiosamente, la CTSC, que paradójicamente estaba llamada a ser una ley contra la moderna esclavitud. Encontraba así Nestlé en la CTSC el safe

59 Hemos de decir que, con anterioridad, en su jurisprudencia en relación con la UCL, el Tribunal Supremo de California había señalado que se creaban «puertos seguros» frente a las acciones de responsabilidad cuando «el legislador ha permitido ciertas conductas o ha abordado una cuestión y ha concluido que no ha lugar a entablar acción». Por lo tanto, si se da una de esas dos circunstancias, no se podrá invocar la UCL para asaltar dicho «puerto» alegando que la conducta (u omisión) permitida o no sancionada es ilícita. Esta misma doctrina había sido reconocida en otras sentencias en relación con la $C L R A$ y la $F A L$, normas ambas también alegadas por los demandantes. 
harbor en el que protegerse frente a las pretensiones de los demandantes. $\mathrm{Y}$ es que, en efecto, el Tribunal desestimó la demanda al entender que las reclamaciones en ella contenida encontraban un obstáculo legal en la safe barbor doctrine.

El demandado alegó que la CTCS creaba un safe harbor para ella ya que dicha norma tan solo exige que las empresas divulguen de forma específica en su web sus esfuerzos por erradicar la esclavitud y la trata de seres humanos en su cadena de proveedores. Pero también especifica la ley los 5 concretos puntos sobre los que tiene que divulgar información. Como bien subrayó el juez, la CTCS no obliga a las empresas sujetas a la ley a realizar acciones contra la esclavitud o la violación de derechos humanos; simplemente deben decir en sus websites si lo hacen o no. De hecho, los demandantes no alegaron que Nestlé no cumplía con la CTCS, sino que sostenían que Nestlé estaba obligada a hacer pública la probabilidad de que una concreta lata de «Fancy Feast» contuviera pescado obtenido mediante trabajos forzosos. La multinacional argumentó que la reclamación era improcedente de acuerdo con la safe harbor doctrine ya que el legislador de California ya había abordado el tema de las informaciones en la CTCS decidiendo no exigir que se publicase una información como la requerida por los demandantes.

Frente a las diversas sentencias alegadas por Nestlé en las que se aplicó la doctrina del safe harbor ${ }^{60}$, los demandantes alegaban que en todas ellas las conductas denunciadas estaban expresamente permitidas por diferentes normas, mientras que la CTCS no autorizaba expresamente la no divulgación de la existencia de trabajos forzosos en la cadena de proveedores, por lo que la conducta de Nestlé no se encontraba a salvo en un «puerto seguro».

De algún modo, los demandantes proponían una interpretación más restrictiva de la doctrina que solo «pusiera a salvo» actos expresamente permitidos o exigidos, pero no aquellos no autorizados de forma específica, invocando para ello distintas sentencias en las que se había entendido que

60 Por ejemplo, el caso Ebner v. Fresh Inc., donde se alegaba que un tratamiento para labios violaba las UCL, CLRA y FAL dado que solo indicaba la cantidad neta de producto y no la que realmente podía extraer el consumidor de forma razonable teniendo en cuenta la forma del recipiente. Se desestimó la demanda ya que la norma que abordaba esa cuestión solo exigía indicar la cantidad neta de producto y no la que «razonablemente puede extraer el consumidor». El legislador entendía que, con imponer esa obligación, el consumidor ya estaba protegido de forma adecuada. En el mismo sentido v. Alvarez v. Chevron Corp.; Lopez v. Nissan N. Am., Inc, 201 Cal. App. 4th 572, 591-92; Loeffler v. Target Corp. 58 Cal. 4th 1081, 1126 (2014); Pom Wonderful LLC, 2013 WL 543361 (todas ellas mencionadas en el Auto). 
no era aplicable la mencionada doctrina ${ }^{61}$. Sin embargo, el juez señaló que esos casos alegados eran distintos al aquí analizado, dado que, en aquellos, los demandados buscaban el safe harbor en leyes que no eran aplicables a la situación jurídica. Solo en uno de los casos alegados, Davis v. HSBC Bank $N e v a d a^{62}$, se invocaba una ley aplicable a la relación jurídica. Sin embargo, y en relación a ese caso concreto, el Auto consideró que el asunto, aunque similar, no era idéntico ni equiparable, ya que la ley invocada en el caso Davis no abordaba la cuestión de si era exigible la divulgación de determinada información (comisiones anuales en todos los anuncios de tarjetas de crédito), sino solamente abordaba la cuestión de la información sobre estas comisiones en el caso de que existiera un desencadenante que requiriera la divulgación, y no en otros casos. En cambio, afirma el Auto, la CTCS sí que trataba directamente la cuestión de qué informaciones debían facilitar las empresas a los consumidores sobre potenciales riesgos de trabajo forzado en su cadena de proveedores.

La idea que hay detrás del Auto es que no procede la doctrina del safe harbor cuando la ley que se invoca no guarda relación con la conducta denunciada, pero sí cuando la ley que se pretende utilizar como puerto seguro ha contemplado la situación y ha decidido no establecer una acción para exigir esa conducta. Si interpretamos de modo muy amplio la doctrina, puede llegarse a soluciones como las de Barber v. Nestle, es decir, que con la CTCS ya se han agotado todas las posibilidades de exigir información a una empresa en relación con la esclavitud y la trata de seres humanos en su cadena de suminis-

61 Aron v. U-Haul Co. of Cal. (143 Cal. App. 4th 796, 801 [Cal. Ct. App. 2006]); Klein v. Chevron U.S.A., Inc.; Doe v. SuccessfulMatch.com, 70 F. Supp. 3d 1066, 1081 (N.D. Cal. 2014); Torres v. $7 C$ Penney Corp., Inc. (N.D. Cal. May 8, 2013). En todas ellas se consideró que no procedía admitir la safe harbor doctrine.

62691 F.3d 1152; 2012 U.S. En este caso, un consumidor había visto un anuncio de una tarjeta de crédito, pero el anuncio no mencionaba que la tarjeta tenía una comisión anual. Tras abrir la cuenta y pagar la comisión, el consumidor demandó por considerar que la falta de indicación de la misma constituía una violación de la UCL. El demandado invocó la doctrina del «puerto seguro» al existir una ley (Regulation Z 12 C.F.R. 226.1 y ss. que puede consultarse en <https:// www.law.cornell.edu/cfr/text/12/part-226>) que establecía que cuando una entidad de tarjetas de crédito crea un anuncio indicando el interés del crédito se le exige ofrecer informaciones adicionales, tales como comisiones anuales. En este asunto el Tribunal estimó que no era aplicable la safe harbor doctrine ya que solo se establecía que en caso de que el anuncio contuviera un término tal como un interés crediticio, se desencadenaría el deber de aportar esa información complementaria. Por lo tanto, decidió que no había ninguna disposición que de modo positivo permitiera la ausencia de indicación de comisiones anuales en los anuncios. 
tro. Sin embargo, si se hace una aplicación más afinada y restrictiva, y exigimos una mayor proximidad entre la conducta objeto de reclamación y las reguladas por la ley, la doctrina rara vez será aplicable.

En el fondo, la discrepancia entre los demandantes y el tribunal radica en que mientras aquellos consideran que la doctrina solo es aplicable cuando la ley expresamente permite una conducta, el tribunal afirma -con base en la jurisprudencia del Tribunal Supremo de California- que la doctrina se aplica tanto cuando el legislador permite una conducta como cuando bas considered a situation and concluded that no action should lie $e^{63}$.

El tribunal afirmó que, en su día, el legislador de California consideró la cuestión de qué información deben divulgar las empresas con posible trabajo forzado en su cadena de proveedores, y decidió que solo exigiría desvelar la información específicamente indicada, sin establecer acciones afirmativas para combatir la trata de seres humanos. Es más, no se requiere de estas empresas otra cosa que publicar en sus sitios webs las acciones que realizan, dejando en manos del consumidor la decisión de cómo usan esa información para decidir en sus compras ${ }^{64}$. Fuera de eso, la ley deja libertad a las empresas para hacer (o no) lo que quieran por afrontar la trata de seres humanos o el trabajo forzado, siempre y cuando faciliten las informaciones específicamente indicadas en la ley. Así, de los términos legales es imposible aceptar la petición de los demandantes en la que alegan que la Ley de California de protección del consumidor exige a las empresas realizar manifestaciones que vayan más allá de lo que exige la $C T C S$.

La clave de todo el asunto, es que se obliga solo a hacer públicos los esfuerzos que se hacen para eliminar la trata de personas en su cadena de proveedores, no a indicar las posibles violaciones de los derechos humanos que se producen en dicha cadena.

Produce cierta perplejidad, por no decir que crea una auténtica paradoja, que haya que acudir a estos argumentos un tanto formalistas. La adopción por parte del legislador de California de la CTCS fue celebrada en su momento por constituir un ejemplo de esfuerzo valiente por mejorar las condiciones labora-

63 Cel-Tech Coms., Inc. v. L.A. Cellular Tel. Co., Cal. 4th 163, 182 (1999). En dicha sentencia se afirmó que un tribunal no puede ignorar lo que ha establecido el Legislador e imponer sus propias concepciones sobre lo que es justo o injusto.

64 Como señalábamos en el apartado precedente, with every dollar that we spend, we vote for the world we want, se deja que sea el consumidor el que diga qué clase de mundo quiere hacer con el uso de su dinero. 
les a nivel mundial (no solo de California). Por eso, choca especialmente que esta ley se pueda invocar como un escudo frente a demandas que guardan relación con hechos tan lamentables. No entramos a prejuzgar si bajo las leyes de California cabe exigir la divulgación de estas informaciones en etiquetados, ni tampoco la culpabilidad de las empresas demandadas. Pero, en todo caso, una ley que buscaba facilitar que los consumidores y otros agentes pudieran contribuir con sus decisiones responsables a la lucha contra la trata de personas, no debería servir de obstáculo para que se exijan divulgaciones de información por otras vías distintas a las de la página web. De lo contrario, la CTCS puede convertirse en la paradoja de ser un safe harbor que ampare aquello por lo que nació, la lucha contra la esclavitud.

\section{Conclusiones}

Comenzábamos poniendo de relieve la importancia de la interacción entre los derechos humanos y las empresas transnacionales y la dificultad fáctica de encontrar recursos efectivos para las víctimas. Aunque se han explorado distintas opciones la conclusión es que sigue siendo tremendamente difícil la lucha a la que se enfrentan los defensores de los derechos humanos en todo el mundo.

La conclusión sin embargo que queremos enfatizar es la necesidad de sentar las bases para la creación de foros alternativos para las víctimas de ilícitos internacionales perpetrados por empresas transnacionales. Para ello, y conforme a compromisos internacionales como pueden ser los nuevos Objetivos de Desarrollo Sostenible, o los diferentes tratados internacionales existentes que garantizan el acceso a la justicia, los Estados podrían intentar implementar a nivel nacional distintas normas de due diligence de modo que se garantizase un control más efectivo de las cadenas de suministro y con ello, colmar este «ángulo muerto» del derecho internacional.

Siguiendo esta línea, para la creación de normas de hard law en tema de empresas y derechos humanos, se podría evaluar también el impacto que puede tener la creciente praxis jurisprudencial ${ }^{65}$ relativa a la doctrina del foro de

65 Frente a la ola de impunidad en que las empresas multinacionales parecen moverse, Canadá, Holanda, Reino Unido, Francia y Suiza, entre otros, están promoviendo la utilización de la 
necesidad ${ }^{66}$. Mecanismo éste seguramente excepcional que se activaría en todos los casos en los que resultara imposible para las víctimas acudir a la justicia en el interior del Estado en cuyo territorio se verificaron las violaciones y que sobre las mismas no se puedan activar los órganos internacionales creados con el fin de luchar contra la impunidad, por falta de jurisdicción, ratione materiae, personae o temporis. Para su activación resultaría necesario el cumplimiento de algunos requisitos ${ }^{67}$ :

The application of the doctrine generally requires the existence of five elements: (1) the absence of jurisdiction in the forum seized of the matter; (2) the requirement of some connection with that forum; (3) the impossibility of bringing the proceedings in the foreign forum with jurisdiction; (4) the reasonableness of requiring the plaintiff to bring the proceedings in that foreign forum; and (5) the absence of fair trial in the foreign forum.

Esta podría ser la opción más clara que tenemos para la creación de foros alternativos y de protección contra la violación de derechos humanos.

En todo caso y para concluir, decíamos al inicio que las víctimas de las violaciones de derechos humanos cometidos por empresas transnacionales eran en el ordenamiento jurídico actual un enorme silencio de justicia material. Un silencio tocado fortísimo. Si una imagen vale más que mil palabras, los hechos a los que nos hemos referido quedarían ilustrados con la imagen

doctrina del foro de necesidad, como mecanismo residual y excepcional, para que se dé la posibilidad a las víctimas de acceder a la justicia delante sus tribunales. Un caso que merece ser citado es sin duda alguna Choc v. Hudbay Minerals, en el que el Tribunal Superior de Justicia de Ontario, abrió el camino para que los tribunales canadienses admitieran su competencia y decidieran sobre el fondo en asuntos relativos a ilícitos civiles y en relación con las actividades de las empresas canadienses o sus subsidiarias en el extranjero (Superior Court of Justice of Ontario Choc v. Hudbay Minerals, W-II-423077, 2013). Sobre este caso vid. en concreto IMAI, S., «El Sistema Judicial Canadiense y La Empresa Minera Hudbay en Guatemala», Comparative Research in Law \& Political Economy, Research Paper, n. ${ }^{\circ} 11$ (2013), disponible <http://digitalcommons.osgoode.yorku.ca/cgi/viewcontent.cgi? article=1260\&context=clpe>, 2013 (marzo 2018).

66 Marullo, $M^{\text {a }}$. Ch., «La lucha contra la impunidad: el Foro Necessitatis», InDret, n. ${ }^{\circ} 3$ (2015), accesible en <http://papers.ssrn.com/sol3/papers.cfm?abstract_id=2698185>, 2015 (febrero 2018).

67 NWAPI, CH., «Jurisdiction by Necessity and the Regulation of the Transnational Corporate Actor», Utrecht fournal of International and European Law, 24 (2014), <http://dx.doi.org/10.5334/ ujiel.cb>, 2014 (marzo 2018). 
de la lápida del compositor SCHNiTTKE en Moscú ${ }^{68}$. Un silencio de duración indefinida, para ser tocado fortississimo.

Es nuestra obligación, como el de un buen director de orquesta, poner fin a esta situación; y como lo hacen los directores de orquesta, esto se hace con un simple gesto. Legislando. Contamos con herramientas y cierta predisposición de los tribunales. Aprendamos del camino que nos ha enseñado California y tratemos de perfilar legislación capaz de proteger, respetar y reparar el daño que de manera silenciosa y continuada están llevando a cabo algunas empresas transnacionales sobre los derechos humanos.

68 En la misma puede verse un calderón sobre un silencio de redonda, sin barras de compás, <https://goo.gl/images/JQLQih> (abril de 2018). En lenguaje musical vendría a significar un silencio casi infinito. 
